Article

\title{
Antistatic Fibers for High-Visibility Workwear: Challenges of Melt-Spinning Industrial Fibers
}

\author{
Rudolf Hufenus ${ }^{1, *}$, Ali Gooneie ${ }^{1}{ }^{\circledR}$, Tutu Sebastian ${ }^{2}$, Pietro Simonetti ${ }^{1}$, Andreas Geiger ${ }^{2}$, \\ Dambarudhar Parida ${ }^{1}\left[\right.$,, Klaus Bender ${ }^{3}$, Gunther Schäch ${ }^{3}{ }^{(1)}$ and Frank Clemens ${ }^{2}$ \\ 1 Laboratory for Advanced Fibers, Empa, Swiss Federal Laboratories for Materials Science and Technology, \\ Lerchenfeldstrasse 5, 9014 St. Gallen, Switzerland; ali.gooneie@empa.ch (A.G.); \\ pietro.simonetti@outlook.com (P.S.); dambarudhar.parida@empa.ch (D.P.) \\ 2 Laboratory for High Performance Ceramics, Empa, Swiss Federal Laboratories for Materials Science and \\ Technology, Überlandstrasse 129, 8600 Dübendorf, Switzerland; tutu.sebastian@empa.ch (T.S.); \\ geigerandreas@web.de (A.G.); frank.clemens@empa.ch (F.C.) \\ 3 EMS-CHEMIE AG, Business Unit EMS-GRILTECH, Via Innovativa 1, 7013 Domat/Ems, Switzerland; \\ klaus.bender@emsgriltech.com (K.B.); gunther.schaech@emsgriltech.com (G.S.) \\ * Correspondence: rudolf.hufenus@empa.ch; Tel.: +41-58-765-7341
}

Received: 19 May 2020; Accepted: 8 June 2020; Published: 10 June 2020

\begin{abstract}
Safety workwear often requires antistatic protection to prevent the build-up of static electricity and sparks, which can be extremely dangerous in a working environment. In order to make synthetic antistatic fibers, electrically conducting materials such as carbon black are added to the fiber-forming polymer. This leads to unwanted dark colors in the respective melt-spun fibers. To attenuate the undesired dark color, we looked into various possibilities including the embedding of the conductive element inside a dull side-by-side bicomponent fiber. The bicomponent approach, with an antistatic compound as a minor element, also helped in preventing the severe loss of tenacity often caused by a high additive loading. We could melt-spin a bicomponent fiber with a specific resistance as low as $0.1 \Omega \mathrm{m}$ and apply it in a fabric that fulfills the requirements regarding the antistatic properties, luminance and flame retardancy of safety workwear.
\end{abstract}

Keywords: bicomponent melt-spinning; safety workwear; nanocomposite; antistatics; carbon black

\section{Introduction}

Antistatic properties in safety workwear are required in order to reduce its electrical resistivity. If friction-induced charge cannot dissipate across the fabric surface and discharge, it may build up and create sparks and static electricity, which can be highly dangerous. Therefore, antistatic clothing is required to prevent fire and explosions while working with flammable liquids and gases, and to avert damage to sensitive electrical components. Antistatic properties can be achieved by a surface treatment that absorbs moisture, resulting in a thin conductive film on the fabric [1,2]. The commercial fiber Resistat ${ }^{\circledR}$ [3], a polyamide 6 (PA6) fiber with a carbon black (CB) coating, is one such example. In respective garments, the treatment can fade or rub off, and the resistivity is influenced by the atmospheric humidity and can increase in dry environments.

In order to make synthetic fibers intrinsically antistatic or conductive, fillers such as $\mathrm{CB}$, carbon nanotubes (CNTs), graphene or metal powders are often used as electrically conductive additives $[1,4,5]$. Typically, the mechanical properties of synthetic fibers change significantly when conductive fillers are used. Since fibers with fillers have very low tenacity, bicomponent fibers with an antistatic compound as a minor element are an interesting approach [6,7]. Respective bicomponent fibers are already commercially available, e.g., "Belltron" (side-by-side) by Kanebo [8] or "Antistat" (core-sheath) 
by Perlon [9]. In this study, we take Belltron B31 [8] as the reference, with the fiber having an electrical resistivity of $\sim 66 \Omega \mathrm{m}$, and the conductive part of the bicomponent fiber one of $\sim 6 \Omega \mathrm{m}$. In this study, these resistivities are applied for comparison with bicomponent fibers or antistatic compounds, respectively.

Another problem with carbon-based fillers is that they lead to unwanted dark colors in the resulting fibers. This reduces the visibility of the corresponding luminous fabrics used for high-visibility (hi-viz) workwear. Garments with hi-viz features are meant to protect workers exposed to risks from vehicles and heavy equipment. Higher visibility can be achieved by using a bicomponent fiber approach, when only a small part of the conductive phase is connected to the surface of the fiber, thus reducing the appearance of the black color. The goal of our study was to achieve good electrical conductivity and simultaneously attenuate the undesired dark color. To enable stable fiber melt-spinning, good electrical conductivity should be realized with low carbon content.

In general, the electrical resistivity of a polymeric material decreases with an increasing content of a conductive filler like carbon black [10]. Gulrez et al. give a good overview of different conductive fillers (e.g., CB, CNTs, graphite, graphene and metal nanoparticles) in polyolefin-based thermoplastics [11]. The formation of the conductive pathways of the fillers is described by the percolation curve, which illustrates the relationship between the quantity of added CB and the achieved electrical resistivity [12]. As soon as the particles start to form an interconnected network, i.e., percolation, the electrical resistivity drops dramatically.

The shape of the percolation curve is mainly affected by the state of dispersion, morphology, content, and intrinsic properties of the conductive filler [10]. It is also well known that the polymer-polymer, polymer-filler and filler-filler interactions play an important role in the equilibrium microstructure of the (nano)composite and hence control the achieved electrical conductivity [13]. Theoretical and experimental investigations suggest that mixing carbon nanoparticles with different shapes and aspect ratios can lead to developing more continuous networks and thus increase the electrical conductivity at a fixed carbon content $[10,13-16]$. Molecular simulations have shown that by increasing the aspect ratio, the equilibrium microstructure of nanoparticles in a polymer matrix changes from a random dispersion to a self-assembled morphology and eventually to a bridging self-assembled network [14]. Besides the particle shape, a range of electrical conductivity can be achieved by varying the amount of filler added to the polymer. In case of CNTs and carbon nanofibers (CNFs), enhanced polypropylene (PP) with a high electrical conductivity can be achieved at relatively low filler loading [11]. Moreover, mechanical models have been developed to address the overall behavior in such polymer (nano)composites [17]. Based on this knowledge, researchers have already investigated the combination of CNT and CB fillers in polymers [18].

In this study, a bicomponent melt-spinning technique to grant antistatic properties to synthetic fibers is reported. First, different conventional approaches to achieve sufficient electrical conductivity with the lowest possible carbon content are assessed, scrutinizing combinations of CBs and CNTs in polyamide, as well as highly loaded CB compounds blended with an immiscible neat polymer (double-percolated conductive network) [19-21]. Secondly, elaborate melt-spinning trials are presented, performed on a custom-made pilot line to determine what material and cross-sectional combinations result in fibers with low electrical resistivity, attenuated blackness and sufficient tensile properties. Finally, the bicomponent antistatic fiber concept is transferred to industrial-scale production and followed through to a prototype antistatic hi-viz safety jacket.

\section{Materials and Methods}

\subsection{Polymers and Compounds}

The neat polymers used to dilute antistatic masterbatches by compounding were the low-densitiy polyethylene (LDPE) $1700 \mathrm{MN} 18 \mathrm{C}$, the medium-density polyethylene (MDPE) $1020 \mathrm{FE}$ 30, the high-density polyethylene (HDPE) $2055 \mathrm{MN}$, the polyamide 6 (PA6) Grilon A26, and the polyamide 12 
(PA12) Grilamid L 20. The base polymer used for fiber melt-spinning was the PA6 Grilon F 34 NL. The commercial antistatic compounds included in this study were the CB-based pigment masterbatches Grilamid L 20 EC, Palamid Black 00-6405 and the polyethylene (PE) compound ColColor RKK E 40/FP, as well as the CNT-containing masterbatch PlastiCyl PA1502. Grilamid FE 11384 is an in-house antistatic compound developed by EMS-CHEMIE (Domat/Ems, Switzerland); compounds No. 6081 and 6082 are 50:50 and 85:15 mixtures of Grilamid L 20 EC and PlastiCyl PA1502, respectively, while compound No. 6083 is a 90:10 mixture of Grilamid FE 11384 and PlastiCyl PA1502. Compounds No. 6237 and 6739 are 50:50 mixtures of ColColor RKK E 40/FP with Grilon F 34 NL and Sabic LDPE, respectively, prepared on a co-rotating $36 \mathrm{~L} / \mathrm{D}$ twin-screw extruder (Collin, Maitenbeth, Germany) by Empa. The pigment masterbatch Palamid White 00-2305 was used to attenuate the dark color of the carbon. Details of the compounds are given in Table 1.

Table 1. Polymers and compounds used in this study. Carbon black (CB), carbon nanotube (CNT) and $\mathrm{TiO}_{2}$ content are specified by the provider.

\begin{tabular}{ccccccc}
\hline Code/No. & Product Name & Provider & $\begin{array}{c}\text { Base } \\
\text { Polymer }\end{array}$ & $\begin{array}{c}\text { CB } \\
\text { Content } \\
\text { (wt } \mathbf{m})\end{array}$ & $\begin{array}{c}\text { CNT } \\
\text { Content } \\
\text { (wt } \%)\end{array}$ & $\begin{array}{c}\text { TiO } \\
\text { Content } \\
(\mathbf{w t} \%)\end{array}$ \\
\hline LDPE & LDPE 1700 MN 18 C & Total & LDPE & - & - & - \\
MDPE & MDPE 1020 FE 30 & Arkema & MDPE & - & - & - \\
HDPE & HDPE 2055 MN & Total & HDPE & - & - & - \\
887 & Sabic LDPE & Sabic & LDPE & - & - & - \\
5432 & Grilon A26 & EMS-CHEMIE & PA6 & - & - & - \\
5528 & Grilon F 34 NL & EMS-CHEMIE & PA6 & - & - & - \\
5793 & Grilamid L 20 & EMS-CHEMIE & PA12 & - & - & - \\
6065 & PlastiCyl PA1502 & Nanocyl & PA12 & - & 15 & - \\
6066 & Grilamid L 20 EC & EMS-CHEMIE & PA12 & 25 & - & - \\
6067 & Grilamid FE 11384 & EMS-CHEMIE & PA12 & 17 & - & - \\
6081 & L-2597 KTI-2 & EMS-CHEMIE & PA12 & 12.5 & 7.5 & - \\
6082 & L-2598 KTI-3 & EMS-CHEMIE & PA12 & 21.25 & 2.25 & - \\
6083 & L-2599 KTI-5 & EMS-CHEMIE & PA12 & 15.3 & 1.5 & - \\
6107 & Palamid Black 00-6405 & BASF & PA6 & 40 & - & - \\
6111 & ColColor RKK E 40/FP & Evonik & PE & 40 & - & - \\
6183 & Palamid White 00-2305 & BASF & PA6 & - & - & 30 \\
6237 & - & - & PE/PA6 & 20 & - & - \\
6739 & - & - & PE/PE & 20 & - & - \\
\hline
\end{tabular}

\subsection{Extrusion and Melt-Spinning}

The polymer compounds were homogeneously mixed using the microcompounder Minilab (Thermo Fisher Scientific, Karlsruhe, Germany) to produce undrawn filaments with high carbon filler content (Figure 1a). Here, the mixture was fed with a top-feeder into a co-rotating conical twin-screw extruder at a speed of $100 \mathrm{rpm}$ and mixed at a temperature of $250{ }^{\circ} \mathrm{C}$. The mixture was cycled towards a backflow slit die channel, equipped with two pressure sensors. After reaching the equilibrium in the pressure sensors, the valve was switched towards a die with diameter $0.5 \mathrm{~mm}$. The filaments were extruded onto a conveyor belt and collected.

For the experiments, masterbatches No. 6107 and 6111, both with $40 \mathrm{wt} \% \mathrm{CB}$, were diluted with the thermoplastics listed in Table 1, to investigate the effect of the CB content on the resistivity. To investigate the effect of additional CNTs, CB masterbatch No. 6107 and CNT masterbatch No. 6065 were diluted with PA12 (No. 5793). Details of the respective compounds and the resulting extrudates are given in Table S1 of Supplementary Materials. 


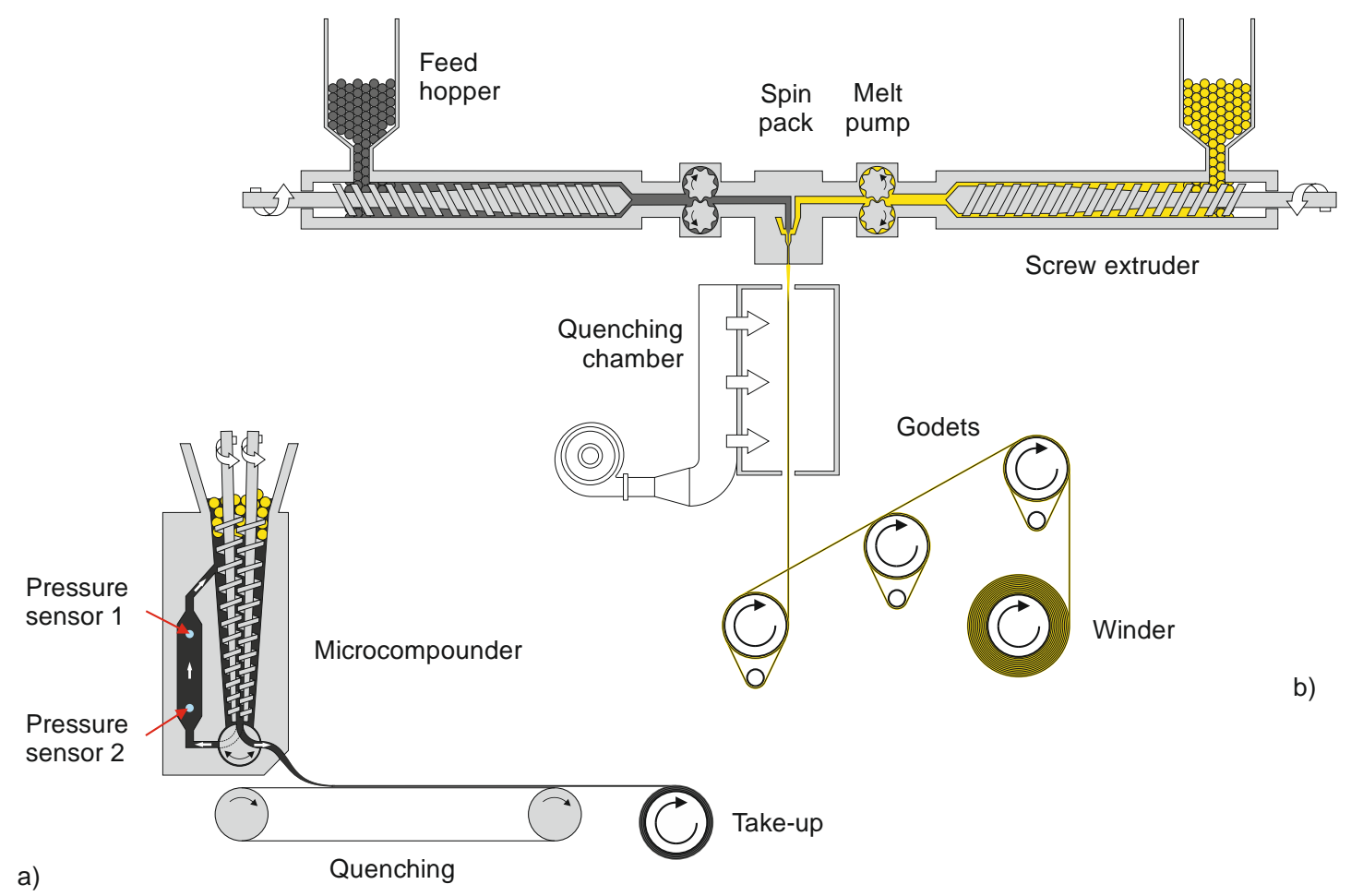

Figure 1. Schematic drawing of (a) the micro compounder with a backflow channel and quenching and take-up units, and (b) of the pilot melt-spinning plant (diameters of godets and winder spool are $100 \mathrm{~mm}$ ). By way of illustration, the colorless polymer is represented in yellow.

The bicomponent fibers were melt-spun in a custom-made pilot plant (Figure 1b), originally built by Fourné Polymertechnik (Alfter, Germany), and described in detail elsewhere [22]. Two types of spinnerets were applied, yielding either "wedge" (Figure 2a) or "sandwich" (Figure 2b) fiber cross-sections. The major component of the bicomponent fiber consisted of PA6 (polymer No. 5528) with $3 \mathrm{wt} \%$ and $7 \mathrm{wt} \%$ of white masterbatch (MB No. 6183), resulting in $0.9 \%$ and $2.1 \% \mathrm{TiO}_{2}$ content in the major fiber part, respectively. Six different antistatic components were introduced (13 or $20 \mathrm{vol} \%$ ) as minor components (Figure 2c): PA6 with $40 \mathrm{wt} \% \mathrm{CB}$ (No. 6107), PA12 with $25 \mathrm{wt} \% \mathrm{CB}$ (No. 6066), PA12 with $21.25 \mathrm{wt} \% \mathrm{CB}$ and $2.25 \mathrm{wt} \%$ CNT (No. 6082), PA12 with $12.5 \mathrm{wt} \% \mathrm{CB}$ and $7.5 \mathrm{wt} \%$ CNT (No. 6081), PA12 with $15.3 \mathrm{wt} \% \mathrm{CB}$ and $1.5 \mathrm{wt} \%$ CNT (No. 6083), and a 50:50 blend of PE containing 40 wt $\%$ CB with PA6 (No. 6237).

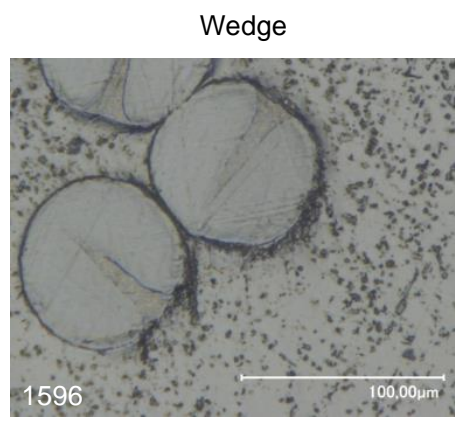

a)

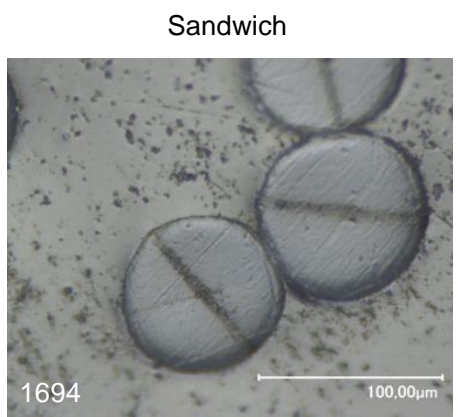

b)

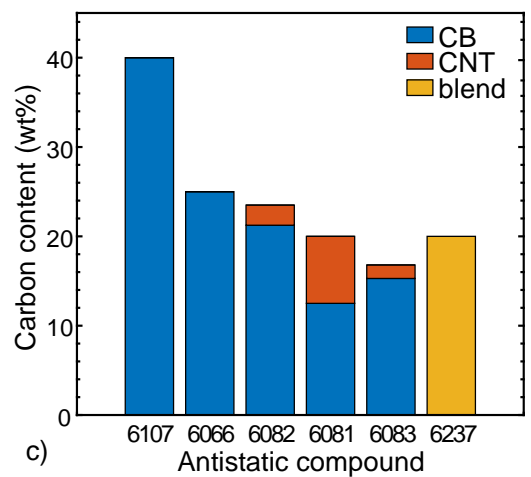

c)

Antistatic compound

Figure 2. Illustration of the antistatic compounds: optical microscopy images of the two types of fiber cross-sections produced: (a) wedge, and (b) sandwich. (c) Carbon content and type of filler in melt-spun bicomponent fibers. 
The two polymer composites were fed from two separate single-screw extruders (Fourné Polymertechnik, Alfter, Germany; length to diameter ratio of 25, major component: $18 \mathrm{~mm}$ diameter, minor component: $14 \mathrm{~mm}$ diameter). Metering pumps (Mahr, Göttingen, Germany) with nominal throughputs of 5.4 and $0.8 \mathrm{~cm}^{3} / \mathrm{min}$ (bicomponent ratio, 87:13), as well as 4.8 and $1.2 \mathrm{~cm}^{3} / \mathrm{min}$ (bicomponent ratio 80:20), transferred the melts into the spin pack. The respective spin pressures and processing temperatures can be found in Table S2. The bicomponent fiber exited the spinneret into the quenching chamber, where it was cooled by air in order to solidify before drawing. Finally, the fiber was taken up, drawn by three heated godets (100 mm diameter, decreasing temperatures: 85 , 50 and $\left.30{ }^{\circ} \mathrm{C}\right)$, and spooled onto a bobbin $(100 \mathrm{~mm}$ diameter). The take-up velocity was $300 \mathrm{~m} / \mathrm{min}$, and the draw ratio, namely the ratio between the winder speed and that of the take-up godet, was varied within the range $1-4$ (resulting in respective winding speeds of $300-1200 \mathrm{~m} / \mathrm{min}$ ).

\subsection{Physical Properties}

The resistivity of the filaments produced by the microcompounder, i.e., their length and cross-section specific electrical resistance, was evaluated with a four-point probes method that uses separate pairs of current-carrying and voltage-sensing electrodes to make more accurate measurements when the resistance is low. The distance between the four probes, connected to a multimeter (SourceMeter 2450, Keithley Instruments, Cleveland, OH, USA), was $10 \mathrm{~mm}$. A two-point measurement was applied to assess the resistivity of the melt-spun bicomponent fibers, as their electrical resistance was high enough in all cases. Here, the fibers were fixed with a conductive silver paste (Acheson, Agar Scientific, Stansted Essex, UK) on two probes with a distance of $10 \mathrm{~mm}$, connected to the multimeter.

The tensile characteristics of the melt-spun fibers were determined using a Statimat ME+ (Textechno Herbert Stein, Mönchengladbach, Germany) with a $10 \mathrm{~N}$ load cell. A series of 10 specimens were tested for each fiber type using a gauge length of $100 \mathrm{~mm}$ and a cross head speed of $200 \mathrm{~mm} / \mathrm{min}$. The fineness was calculated from the weight of a $100 \mathrm{~m}$ long fiber sample.

To study the fiber cross-section, fibers were embedded in epoxy resin and cross-sections prepared with the polisher EcoMet 250 Pro (Buehler, Esslingen am Neckar, Germany). Optical microscopy pictures were taken using a VHX-1000 (Keyence, Mecheln, Belgium) system. Scanning electron microscopy (SEM) was conducted on a Hitachi S-4800 SEM (Hitachi High-Technologies, Krefeld, Germany). As prepared, the fiber samples were coated with $\mathrm{Au} / \mathrm{Pd}(5 \mathrm{~nm})$ prior to analysis.

The surface color of a fiber bobbin was measured using the dual-beam spectrophotometer Datacolor 550 (Datacolor, Rotkreuz, Switzerland) fitted for reflectance measurements, in a wavelength range between $360 \mathrm{~nm}$ and $700 \mathrm{~nm}$. The bobbin was attached to an integrating sphere (diameter $152 \mathrm{~mm}$ ) and illuminated through a slit of defined size, in order to detect the spectrum of the reflected light.

\section{Results and Discussion}

\subsection{Assessment of Different Approaches to Reduce the Resistivity of Compounds}

Before discussing the properties of melt-spun polymer fibers, we establish an assessment of potential approaches to produce conductive compounds for later use in fibers. The electrical conductivity of polymers with carbon fillers is first and foremost influenced by the filler content. Upon diluting the PA6 compound containing $40 \mathrm{wt} \%$ CB (No. 6107) with neat PA12 (No. 5793), the electrical resistivity increases (Figure 3a). Figure 3a shows that, by adding CB in steps of $5 \mathrm{wt} \%$, the resistivity of PA gets roughly 100 times lower per step, until the percolation threshold is reached and the resistivity levels out. Without drawing the filament, a good enough resistivity, compared to the conductive part of the commercial fiber Belltron B31 $(\sim 6 \Omega \mathrm{m})$, is reached at about $24 \mathrm{wt} \%$ CB. Follow-up fiber spinning experiments revealed that a filler content above $20 \mathrm{wt} \%$ resulted in the clogging of the filters and spinneret over time. 

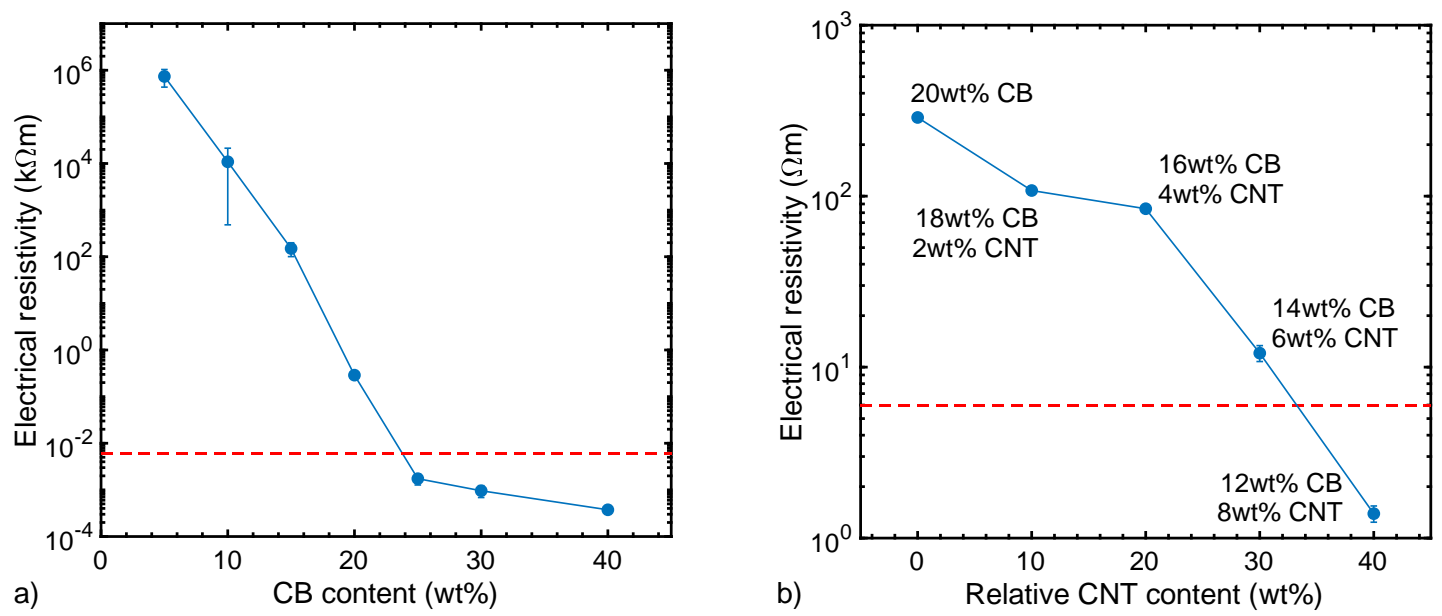

Figure 3. Electrical resistivity of (a) polyamide (PA) filaments produced by microcompounding, as a function of CB content; and (b) compounded/extruded filament as a function of relative CNT addition with respect to the total carbon content (i.e., $\mathrm{CB}+\mathrm{CNT}$ ), which is kept at $20 \mathrm{wt} \%$. For clarification, the absolute $\mathrm{CB}$ and $\mathrm{CNT}$ concentrations of the respective compounds are stated in the graph. The error bars represent double the standard deviation (some of the error bars are too small to be visible; see Table S1). For comparison, the resistivity of the conductive part of the commercial bicomponent fiber Belltron B31 is plotted as dashed line.

Upon diluting a PE compound containing $40 \mathrm{wt} \%$ CB (No. 6111) with PE (No. 887) in order to achieve $20 \mathrm{wt} \% \mathrm{CB}$ in the mixture, the resistivity reaches $0.23 \pm 0.01 \Omega \mathrm{m}$ after once mixing in the twin-screw extruder Collin (Table S1). Upon mixing the same compound (No. 6739) a second time in the same way, the resistivity increases a thousand-fold to $0.32 \pm 0.15 \mathrm{k} \Omega \mathrm{m}$ (Table S1), which can be explained by the breakdown of percolated networks of aggregated CB. Compounding a similar material combination (50 $\mathrm{wt} \%$ LDPE with $50 \mathrm{wt} \%$ 6111) in the microcompounder leads to an abrupt increase in resistivity up to $7.8 \pm 0.4 \mathrm{M} \Omega \mathrm{m}$ (Table S1, Figure $4 \mathrm{a}$ ). This trend shows the significant effect of intensive mixing on the formation and breakdown of percolated networks of conductive CB fillers in the polymer matrix, as explained by the so-called "aggregate-network" model [23].

Fillers' properties such as their particle size and aspect ratio are known to influence the electrical conductivity of polymer (nano)composites [14-16]. In particular, the dispersion quality, aspect ratios of carbon nanoparticles, and formation of nanoparticle networks with continuous pathways for efficient electron transport are largely interconnected. Various studies have shown the synergistic effect of a CB-CNT hybrid filler on the electrical conductivity of the polymer composite [24]. Thus, we evaluated different CB-CNT combinations between 5 and $40 \mathrm{wt} \%$ carbon, with $0-100 \mathrm{wt} \% \mathrm{CNT}$ content. Due to the higher area to weight ratio of CNTs, a lower filler loading is needed to reach the percolation threshold, which results in a reduced resistivity (Figure $3 b$ ). Figure $3 b$ shows that, with high enough CNT loading, the overall carbon content to reach a good enough resistivity can be below $20 \mathrm{wt} \%$.

Polymer nanocomposites based on CB-CNT mixtures still retain their undesired black color despite their advantage of higher conductivity at lower carbon contents. In an attempt to further reduce the blackness of the extrudates while preserving the electrical conductivity, the PA6 and PE compounds containing $40 \mathrm{wt} \%$ CB (No. 6107 and 6111, respectively) were diluted with either neat polyethylenes (HDPE, MDPE or LDPE) or polyamides (PA6 and PA 12, No. 5432 and 5793, respectively). As a result, carbon particles mainly accumulated in one phase or at the interface of the polymers and thus formed the so-called double-percolated conductive networks $[20,25,26]$. The concept of double-percolated polymer blends seems to work as long as the polymers are immiscible (Figure 4a). Mamunya [27] suggested that, among immiscible polymers, $C B$ tends to accumulate more in the polymer with lower surface tension. The distribution of $\mathrm{CB}$ in two different polymer phases can be predicted based on their interfacial tension and wetting behavior [26]. The distribution tendency of $\mathrm{CB}$ in immiscible polymer 
blends found in literature is summarized in Table 2 (see also [28]). Based on the surface energies of PE [29], PA6 [29,30], PA12 [30,31] and CB [21], as well as their temperature dependencies, we estimated the wetting parameters to determine the distribution of $C B$ in our blends [31]; see Table 2. We predict that $\mathrm{CB}$ selectively locates either at the interface of PE/PA6 or in the PE phase of PE/PA12 blends. Thus, a double-percolated conductive network can be envisioned in both immiscible blends. In consequence, high conductivity could be achieved at lower carbon contents. However, the transfer of this concept to bicomponent antistatic fibers failed, as is explained in the next section.
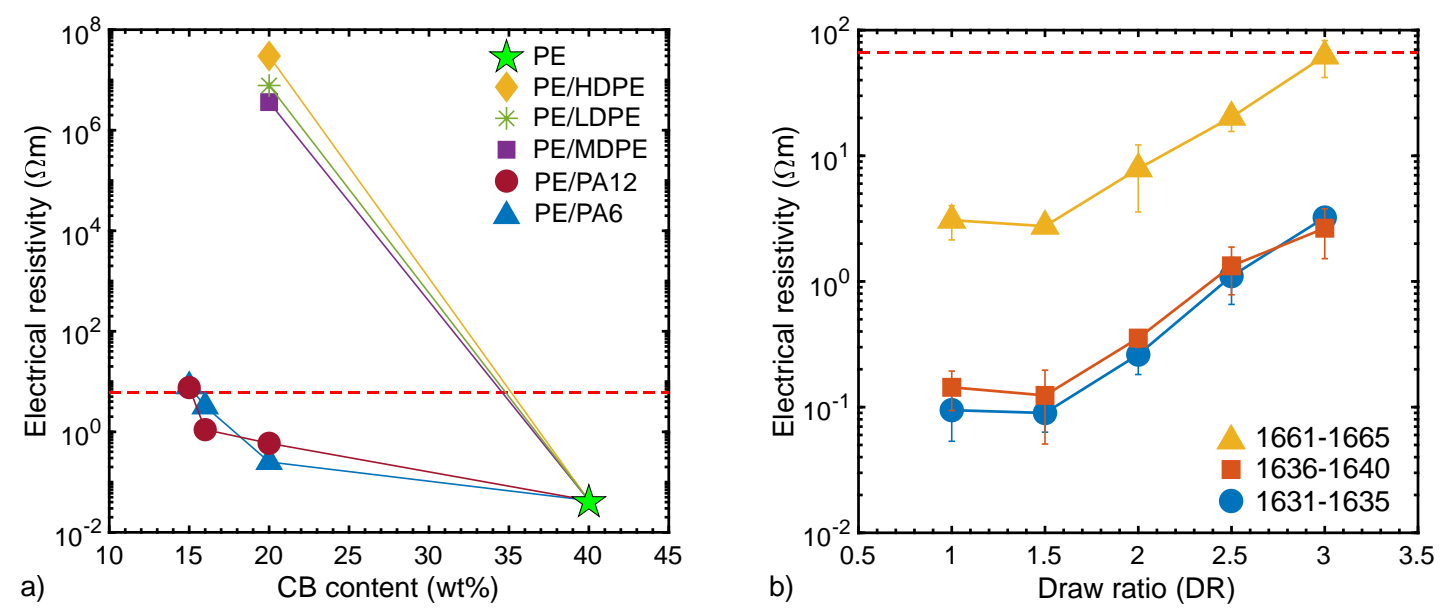

Figure 4. (a) Electrical resistivity of compounded/extruded filament of PE masterbatch No. 6111, blended with different polymers. PE = No. 6111; PE/PE: 50\% No. 6111 diluted in HDPE, LDPE and MDPE, respectively; PE/PA12: 37.5\%, 40\% and 50\% No. 6111 diluted in No. 5793; PE/PA6: 37.5\%, $40 \%$ and $50 \%$ No. 6111 diluted in No. 5432. The miscible compounds show a very high resistivity, whereas the immiscible blends reveal a resistivity in the range of the value of the conductive part of the commercial bicomponent fiber Belltron B31 ( 6 $\Omega \mathrm{m}$, dashed line). (b) Electrical resistivity of selected melt-spun bicomponent fibers with $13 \mathrm{vol} \%$ antistatic compound (Table S3) as a function of draw ratio (DR). For comparison, the resistivity of the commercial bicomponent fiber Belltron B31 $(\sim 66 \Omega \mathrm{m})$ is plotted as dashed line. The error bars represent double the standard deviation (see Tables S1 and S3); some of the error bars are too small to be visible.

\subsection{Physical Properties of Bicomponent Fibers}

Based on the results presented so far, it appears that the most convenient approach to overcome the intrinsic resistivity of synthetic fibers is to add carbon particles in high concentrations to the polymer matrix and melt-spin them into bicomponent fibers. In bicomponent melt-spinning, two polymers of different chemical/physical natures are extruded from one spinneret to form a single fiber [6]. This approach, with an antistatic compound as a minor element, prevents a severe loss of the tensile strength of the melt-spun fibers caused by a high additive loading.

A design of experiment (DoE) was chosen that covers a theoretical maximum of 336 combinations. In the end, 110 different bicomponent fibers were melt-spun and analyzed (Table S3). The sandwich cross-sections were regular in shape for all respective fibers (Figure $2 b$ or Figure S1a-c). The shape of the wedge cross-sections, on the other hand, varied strongly as a function of the viscosity differences of the two compounds constituting the bicomponent fibers (Figure 2a or Figure S1d-i). For all cross-sections, the shape was maintained when the fibers were drawn (Figure S1a-f).

$\mathrm{TiO}_{2}$ was used to partially bury the conductive element inside a dull bicomponent fiber, and to attenuate its undesired dark color. As an effect of increased draw ratio, we noticed that the scattering efficiency of the $\mathrm{TiO}_{2}$ pigments decreased with increasing spatial dispersion, while the coverage of the carbon black was largely unaffected (Figure 5). 
Table 2. Distribution tendency of CB in immiscible polymer blends. Polymers considered: polymethyl methacrylate (PMMA), polypropylene (PP), polyoxymethylene (POM), polyvinylidene fluoride (PVDF), ethylene vinyl acetate (EVA), polystyrene (PS) and acrylonitrile butadiene styrene (ABS).

\begin{tabular}{|c|c|c|c|c|}
\hline \multicolumn{3}{|c|}{ Blend Composition } & \multirow{2}{*}{$\begin{array}{c}\begin{array}{c}\text { Distribution } \\
\text { Tendency of CB }\end{array} \\
\text { Interface }\end{array}$} & \multirow{2}{*}{$\begin{array}{c}\text { Reference } \\
\text { Sumita et al. [20] }\end{array}$} \\
\hline PMMA & PP & $\mathrm{CB}$ & & \\
\hline PMMA & HDPE & $\mathrm{CB}$ & Interface & Sumita et al. [20] \\
\hline LDPE & PP & $\mathrm{CB}$ & LDPE & Mamunya [27] \\
\hline LDPE & POM & $\mathrm{CB}$ & Interface & Mamunya [27] \\
\hline HDPE & PVDF & $\mathrm{CB}$ & HDPE & Feng et al. [32] \\
\hline PA66 & PP & $\mathrm{CB}$ & PA66 & Zoldan et al. [33] \\
\hline PA6/6-9 & $\mathrm{PP}$ & $\mathrm{CB}$ & PA6/6-9 & Tchoudakov et al. [34] \\
\hline PP & EVA & $\mathrm{CB}$ & EVA & Huang et al. [35] \\
\hline PP & PS & $\mathrm{CB}$ & PS & Tan et al. [36] \\
\hline LDPE & EVA & $\mathrm{CB}$ & LDPE & Yu et al. [37] \\
\hline PS & PMMA & $\mathrm{CB}$ & PS & Pan et al. [38] \\
\hline HDPE & PP & $\mathrm{CB}$ & HDPE & Xu et al. [39] \\
\hline PP & PA6 & $\mathrm{CB}$ & PA6 & Chen et al. [40] \\
\hline ABS & PA6 & $\mathrm{CB}$ & PA6 & Wu et al. [41] \\
\hline PS & PA6 & $\mathrm{CB}$ & PA6 & Xu et al. [39] \\
\hline PMMA & PA6 & CB & PA6 & Xu et al. [39] \\
\hline PE & PA12 & $\mathrm{CB}$ & PE & This study \\
\hline PE & PA6 & $\mathrm{CB}$ & Interface & This study \\
\hline
\end{tabular}
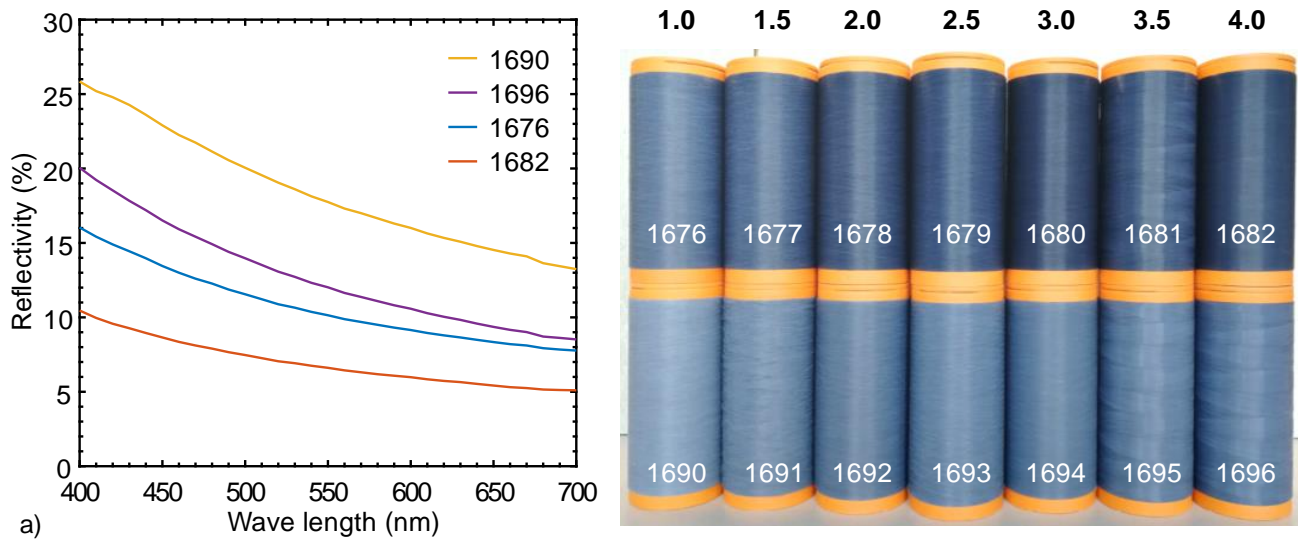

DR

$0.9 \mathrm{wt} \% \mathrm{TiO}_{2}$

$2.1 \mathrm{wt} \% \mathrm{TiO}_{2}$

Figure 5. Grayness of selected filaments as a function of the draw ratio (DR) and $\mathrm{TiO}_{2}$ content: (a) reflectivity (in \%) measured directly on the bobbins; (b) photograph of fiber bobbins.

The tensile properties of selected fibers are listed in Table S4. Additionally, Figure 6a shows the load-strain behavior of melt-spun bicomponent fibers, which is typical for PA6 fibers [42,43]. In the undrawn state (DR 1), the fibers show considerable plastic deformation under stress. With an increasing draw ratio, the fibers gain in stiffness and resilience. A draw ratio of 4 is about the maximum that can be achieved without breaking the fiber, which corresponds to an elongation of $300 \%$ of the undrawn (DR 1) fiber. These findings indicate that the antistatic compound has an industrially tolerable impact on the tensile properties, as long as its proportion is small (at or below $20 \mathrm{vol} \%$ ). As expected, the specific tensile strength (in cN/tex) is reduced in comparison to a pristine PA6 filament (Table S4), mainly since the antistatic compound contributes to the weight but not to the tensile strength. Tex, a direct measure of the linear fiber density, is the mass in grams per $1000 \mathrm{~m}$ of the fiber. 

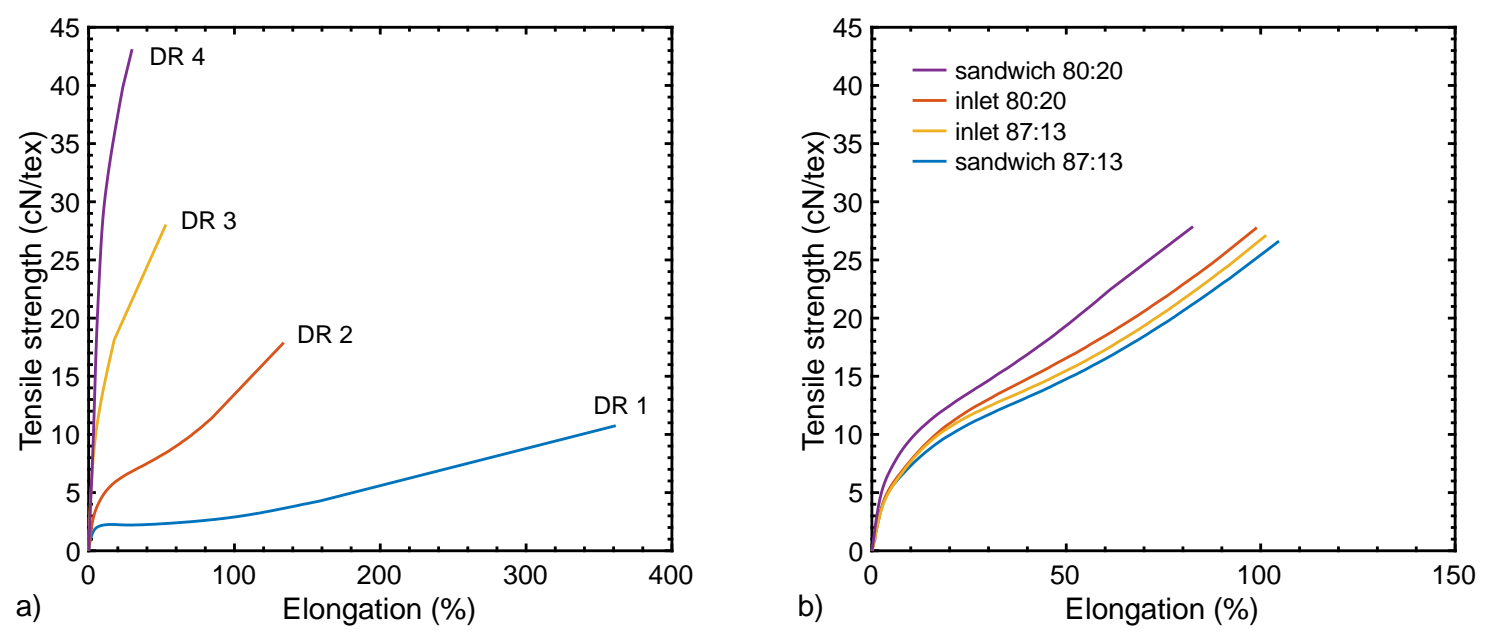

Figure 6. Average tensile stress-strain curves of selected fibers containing 13\% of PA12 with $15.3 \mathrm{CB}$ and 1.5 CNT as the antistatic component: (a) sandwich cross-section fiber at different draw ratios (1: 1647, 2: 1649, 3: 1651, 4: 1653); (b) wedge (80/20: 1623, 87/13: 1628) and sandwich (80/20: 1644, 87/13: $1650)$ cross-section fibers with draw ratio 2.5.

Figure $6 \mathrm{~b}$ also illustrates that the influence of the cross-section type on the load-strain behavior is small. The maximum tensile strength seems to be slightly higher with the wedge cross-section, most probably due to a smaller influence on the integrity of the fiber (see Figure 2a). Furthermore, the increased stiffness of the sandwich fiber with a higher antistatic portion can be explained by a mobility constraint of the load-bearing part by the antistatic fraction. Such a constraint seems not to affect the wedge fibers, most probably because of the above-mentioned smaller influence on the load-strain behavior.

Scanning electron microscopy pictures of selected sandwich fiber surfaces (Figure 7) show the following. The surface of the antistatic compound shows a higher roughness than that of pure PA6, which can be explained by the tendency of $\mathrm{CB}$ to agglomerate within the polymer matrix. When the base polymer of the antistatic compound and the main fiber component are miscible (Figure 7a,b), the sandwich filling is perfectly integrated in the fiber, but if they are immiscible (Figure $7 \mathrm{c}, \mathrm{d}$ ), the two components tend to separate, which could lead to fibrillation when a mechanical stress is applied. However, no transversal cracks were found in the sandwich fillings of the drawn fibers (Figure $7 \mathrm{~b}, \mathrm{~d}$ ), thus the increasing electrical resistivity at higher draw ratios (Figure $4 \mathrm{~b}$ ) cannot be explained by a rupture of the antistatic compound.

The increase in the resistivity when the fiber is melt-drawn can be ascribed to a spatial dilution of the carbon filler (Figure $4 \mathrm{~b}$ ). Here, a draw ratio (DR) of 3 still gives low enough resistivity values. As this is also a reasonable DR for PA6, we mainly consider this DR for the following analysis. As long as the carbon content is above a certain value, the resistivity is only affected by the conductivity of the carbon composite and not by its content ratio within the bicomponent fiber, as shown in Figure $4 \mathrm{~b}$. In other words, it is sufficient that only a small portion of the bicomponent fiber is conductive.

At the same bicomponent ratio (20:80), the shape of the cross-section has no influence when only CB is used (Figure 8a). However, when CNTs are added, the resistivity is reduced in case of the wedge structure. This is probably due to the spinneret channels, which are comparatively narrower to achieve the wedge cross-section. The resulting higher shear improves the dispersion state of the CNTs by breaking the CNT aggregates, leading to lower resistivity [44,45]. 

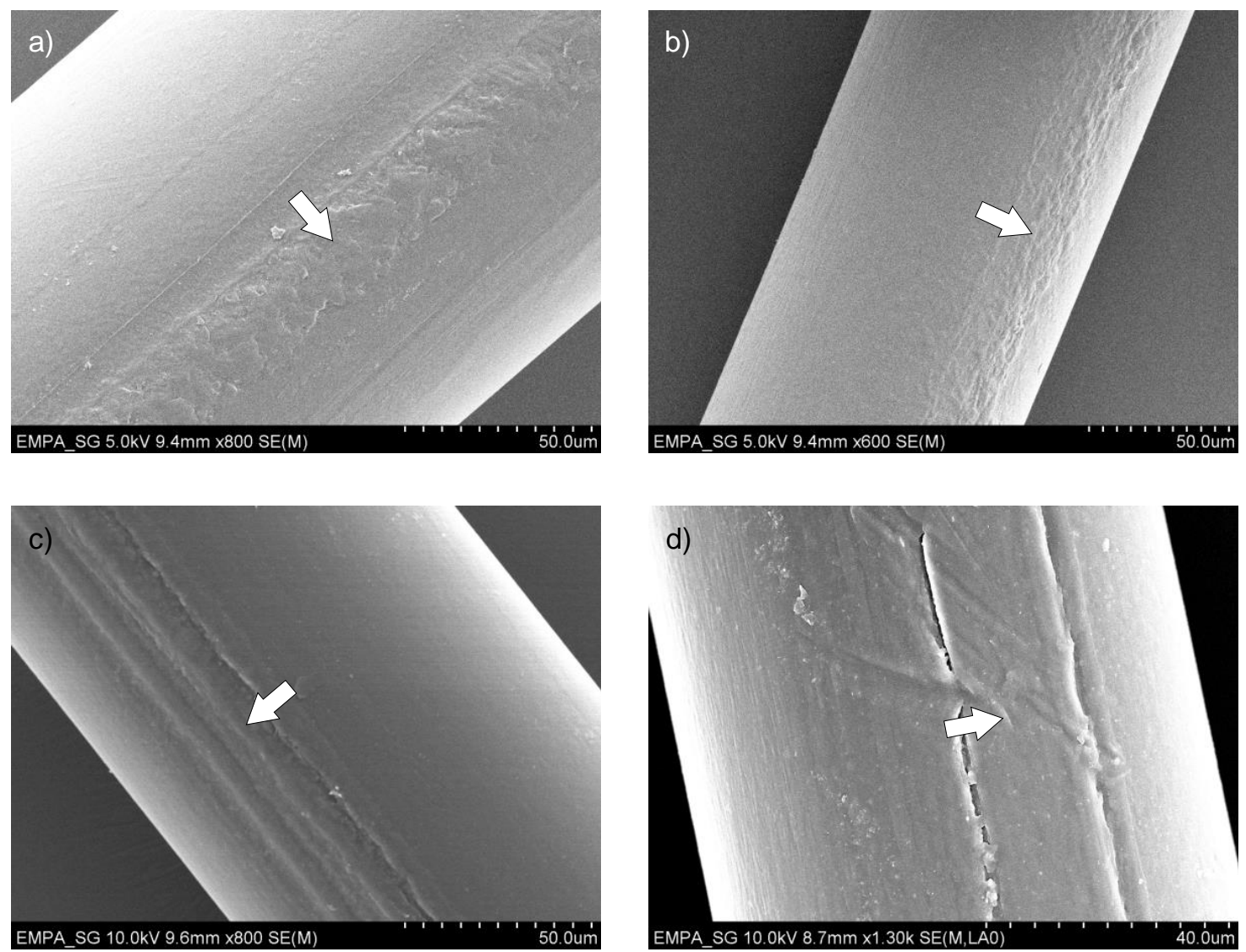

Figure 7. SEM images of selected fiber surfaces. (a,b) Sandwich fibers with antistatic compound No. 6066 (25\% CB in PA12), draw ratios 1 (No. 1581, (a)) and 2 (No. 1583, (b)). (c,d) Sandwich fibers with antistatic compound No. 6237 (50:50 mixture of PA6 and PE with 40\% CB, draw ratios 1 (No. 1669, (c)) and 2 (No. 1671, (d)). Arrows indicate the antistatic compound.
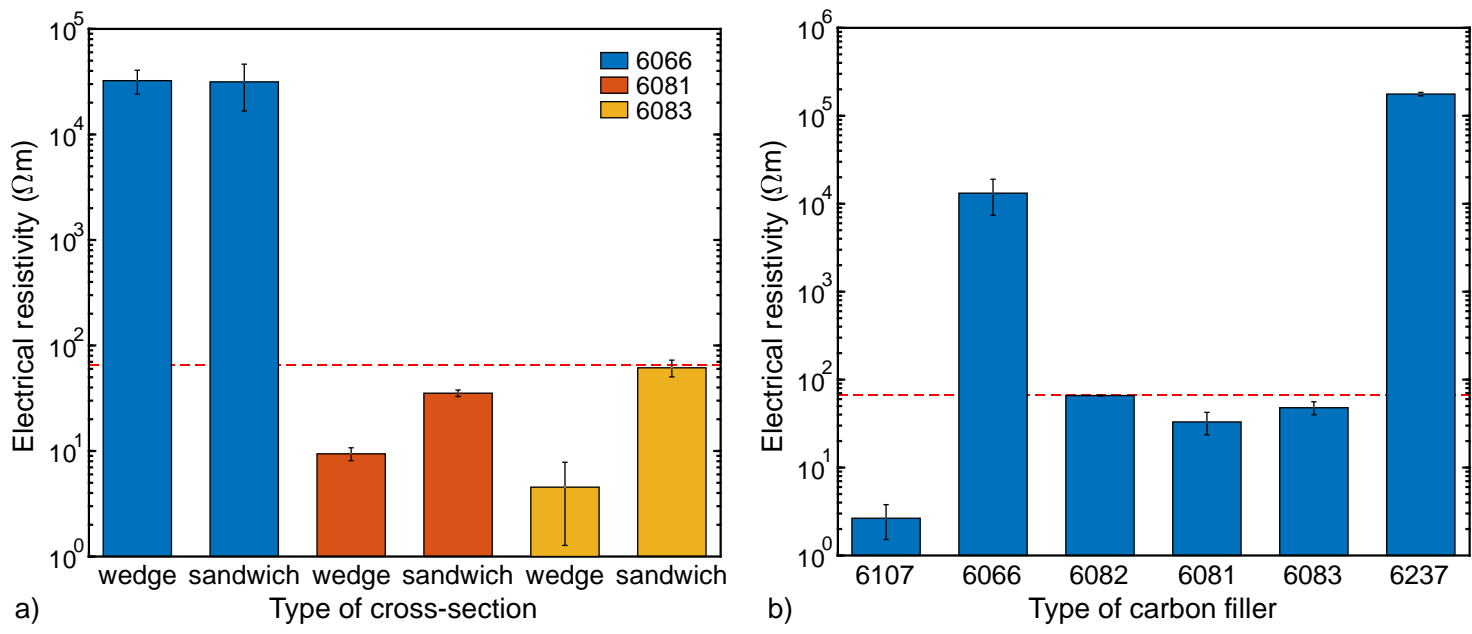

Figure 8. Resistivity of melt-spun bicomponent fibers (DR 3) as a function of the (a) fiber cross-section (fibers with $20 \mathrm{vol} \%$ antistatic compound) and (b) type of carbon filler (sandwich fibers with $13 \mathrm{vol} \%$ antistatic compound). For comparison, the resistivity of the commercial bicomponent fiber Belltron B31 $(\sim 66 \Omega \mathrm{m})$ is plotted as a dashed line. The error bars represent double the standard deviation (some of the error bars are too small to be visible; see Table S3).

Figure $8 \mathrm{~b}$ shows the influence of the type of filler on the resistivity. With $40 \mathrm{wt} \% \mathrm{CB}$ (6107), even with a DR of 3, the percolation threshold is far exceeded and the resulting resistivity is 25 times lower 
than that of the commercial fiber. With $25 \mathrm{wt} \% \mathrm{CB}(6066)$, the dilution of the carbon filler at a draw factor of 3 increased the resistivity by a factor of $\sim 1000$, whereas the twin-screw extruded undrawn filaments had previously shown sufficient conductivity (Figure 3a). The combination of CB and CNTs, on the other hand, resulted in good conductivity (i.e., low enough resistivity) at an overall carbon content below $25 \mathrm{wt} \%$ (6081-6083). Considering the approach with a 50:50 polymer-polymer blend with carbon black in only one of the immiscible polymers (6237), the conductivity was lost after the melt-spinning the blend. We believe that this is due to breakup of the conductive domains within the nonconductive polymer in the narrow channels of the spinneret, which led to losing the double-percolation.

In conclusion, we found that the carbon content can be reduced by applying a mixture of CB and CNTs in the antistatic compound, and by improving the dispersion state of CNTs in the narrow melt-flow channels of a bicomponent spinneret [45]. On the other hand, the grayness can be attenuated by a combination of a low carbon composite ratio in the bicomponent fiber and a high $\mathrm{TiO}_{2}$ loading in the major polymer component. Such an approach would also guarantee good mechanical behavior of the melt-spun fibers.

\subsection{Prototype Production of Antistatic Hi-Viz Workwear}

Upscaling trials on an industrial-scale spinning plant, using the sandwich cross-section approach, showed that all CNT-containing composites led to severe spinning instabilities, finally resulting in filter and spinneret blockage. The main reason for this setback is that the industrial-scale spin-packs and spinnerets are not typically optimized for such a kind of materials. Since developing a new design for the processing equipment was beyond the scope of this research, we were forced to resort to our CNT-free material for industrial melt-spinning. In consequence, the final upscaling trials were performed with the $40 \mathrm{wt} \%$ CB compound (No. 6107), the only feasible conductive composite left in this study.

For both the antistatic composite and main bicomponent fiber polymer (No. 5528), PA6 was used for the upscaling melt-spinning trials at EMS-CHEMIE AG (Domat/Ems, Switzerland). Due to co-extrusion viscosity mismatch, adding $\mathrm{TiO}_{2}$ to the base polymer also led to spinning instabilities; in consequence, the final upscaling trials were performed without $\mathrm{TiO}_{2}$. The lowest bicomponent ratio achievable with the available industrial-scale melt-spinning plant over a prolonged time was $43 \mathrm{vol} \%$ of antistatic compound. Although the processing conditions were far from optimal, we still proceeded to the production of the respective antistatic staple fibers (fineness, $1.2 \pm 0.3$ tex; nominal length, $51 \mathrm{~mm})$. The resulting fibers reached a resistivity of less than $0.1 \Omega \mathrm{m}$, which is three orders of magnitudes better than that of the commercial fiber Belltron B 31 ( $66 \Omega \mathrm{m}$; nominal fineness, 0.3 tex) that we took into consideration as a reference. The overall carbon black content in the fiber, calculated from the CB content of the masterbatch and the bicomponent ratio of the fiber, was $\sim 17 \mathrm{wt} \%$.

In the next step, the Rieter Spin Center (Winterthur, Switzerland) produced a staple fiber yarn by ring spinning, having a fineness of 40 tex. The yarn was composed of $95 \mathrm{wt} \%$ flame retardant polyester staple fibers (Trevira CS, fineness 0.33 tex, nominal length $60 \mathrm{~mm}$ ) and only $5 \mathrm{wt} \%$ of above antistatic staple fiber, resulting in a CB content of $\sim 0.9 \mathrm{wt} \%$ concerning the yarn. With this antistatic yarn, Jenny Fabrics AG (Niederurnen, Switzerland) produced a plain weave fabric (Figure 9), with only one out of eight yarns being antistatic (none of the warp yarns, only every fourth of the weft yarns), the rest being neat flame-retardant staple fiber yarn (Trevira CS, fineness 37 tex). Thus, the final CB content of the fabric was $\sim 0.1 \mathrm{wt} \%$. Finally, the fabric was finished with a luminescent dye by AG Cilander (Herisau, Switzerland). With this fabric, a hi-viz safety workwear jacket was produced by Hüsler Berufskleider AG (Sirnach, Switzerland) and positively tested regarding the most relevant requirements, i.e., surface resistivity (EN 1149-5 [46]), luminescence (EN 471 [47]) and flame retardancy (UL94 [48]). 


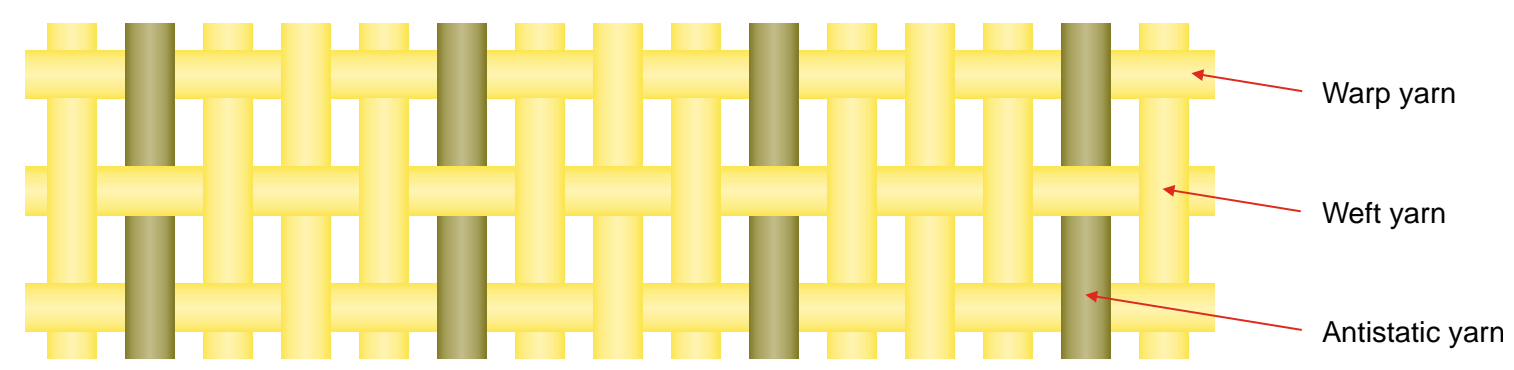

Figure 9. Plain weave fabric with every fourth of the weft yarns being antistatic, the rest being neat flame-retardant staple fiber yarns.

\section{Conclusions}

The use of antistatic fibers in safety workwear is an established technology to prevent friction-induced sparks that can harm delicate equipment or provoke fire and explosions in combustible environments. Despite their blackness, especially objectionable in hi-viz applications, and its negative influence on the tensile properties of fibers, carbon (nano)particles (CB and CNTs) are still the most promising candidates for antistatic compounds. In this study, we assess the potential of various conventional methods of implementing such particles in polymers, in order to increase the electrical conductivity of the host. A rather comprehensive overview of these approaches is offered, which reveals the challenges of upscaling such materials from the lab to pilot to the industrial production of melt-spun fibers.

We show that the embedding of a conductive compound into a bicomponent melt-spun fiber, as a minor component within a $\mathrm{TiO}_{2}$-pigmented main polymer, can result in a fiber with reduced grayness and still-sufficient conductivity and tensile strength. It is discussed that the combination of CB and CNT within one polymer, as well as the blending of a CB compound with a pure immiscible polymer, can both lead to reduced electrical resistivity at maintained carbon content. However, the attempt to melt-spin respective antistatic compounds in a bicomponent approach resulted either in severe processing instabilities or in total failure of the anticipated electrical performance.

Nevertheless, we could successfully develop and produce an antistatic fiber at the industrial scale with an electrical resistivity below $0.1 \Omega \mathrm{m}$, which is about a thousand times better than that of the existing commercial fibers. Out of these fibers, we produced a staple fiber yarn and finally a woven fabric, which was finished with a luminescent dye. From this fabric, a safety workwear jacket was tailored, which fulfilled the relevant standards regarding resistivity, luminescence and flame retardancy.

We conclude by emphasizing that there is still a lot of space for improvement. To realize accordingly optimized antistatic fibers on a large scale, for instance, an auxiliary extruder with comparably small throughput would be required, as well as a special spinneret that takes the viscosities of the carbon composite and the $\mathrm{TiO}_{2}$-pigmented main polymer into account.

Supplementary Materials: The following are available online at http://www.mdpi.com/1996-1944/13/11/2645/s1, Table S1: Electrical resistivity of filaments produced in this study by compounding in a twin-screw extruder, Table S2: Pilot melt-spinning: average spin pressures and processing temperatures, Table S3: Electrical resistivity of fibers produced in this study by melt-spinning, Table S4: Tensile properties of selected fibers produced in this study, Figure S1: Microscopic images of selected fiber cross-sections produced.

Author Contributions: Conceptualization, R.H., K.B. and F.C.; methodology, R.H., A.G. (Ali Gooneie) and F.C.; validation, A.G. (Ali Gooneie); formal analysis, R.H. and F.C.; investigation, R.H., T.S., P.S., A.G. (Andreas Geiger), D.P., G.S. and F.C.; writing-original draft preparation, R.H.; writing-review and editing, R.H., A.G. (Ali Gooneie) and F.C.; visualization, R.H. and A.G. (Ali Gooneie); supervision, R.H., K.B. and F.C.; project administration, R.H.; funding acquisition, R.H., A.G. (Ali Gooneie), K.B. and F.C. All authors have read and agreed to the published version of the manuscript. 
Funding: This research was funded by Innosuisse (Switzerland), grant number 18816.1 PFIW-IW, and Zürcher Stiftung für Textilforschung (Switzerland), grant number 127. Ali Gooneie was supported by the Empa Internal Research Call 2018 in the framework of the "ALLFIN" project.

Acknowledgments: The authors acknowledge the support of Mathias Lienhard in the compounding trials, Benno Wüst in the melt-spinning experiments, and Marion Höhener in the electrical resistivity measurements. We also thank EMS-CHEMIE AG, Rieter Spin Center, Jenny Fabrics AG, AG Cilander and Hüsler Berufskleider AG (all Switzerland) for donations and upscaling trials.

Conflicts of Interest: The authors declare no conflict of interest.

\section{References}

1. Fu, K.; Padbury, R.; Toprakci, O.; Dirican, M.; Zhang, X. 13-Conductive textiles. In Engineering of High-Performance Textiles; Miao, M., Xin, J.H., Eds.; Woodhead Publishing: Cambridge, UK, 2018; pp. 305-334.

2. Molina, J. Graphene-based fabrics and their applications: A review. RSC Adv. 2016, 6, 68261-68291. [CrossRef]

3. Shakespeare Conductive Fibers. Available online: http://www.resistat.com/pdf/rsum2.pdf (accessed on 12 May 2020).

4. Stoppa, M.; Chiolerio, A. Wearable Electronics and Smart Textiles: A Critical Review. Sensors 2014, 14, 11957-11992. [CrossRef] [PubMed]

5. Kong, L.B.; Boey, F.; Huang, Y.; Xu, Z.J.; Zhou, K.; Li, S.; Que, W.; Huang, H.; Zhang, T. Graphene-Based Fibers. Carbon Nanomater. Based Graphene Nanosheets 2017, 27, 303-383. [CrossRef]

6. Hufenus, R.; Yan, Y.; Dauner, M.; Yao, D.; Kikutani, T. Bicomponent Fibers. In Handbook of Fibrous Materials; Wiley: Hoboken, NJ, USA, 2020; Volume 1, pp. 281-313.

7. Hu, C.; Chang, S.-S.; Liang, N.-Y. Fabrication of antistatic fibers with core/sheath and segmented-pie configurations. J. Ind. Text. 2016, 47, 569-586. [CrossRef]

8. Japan KBS Belltron. Available online: http://www.kbs-belltron.com/en/index.html (accessed on 12 May 2020).

9. Perlon Nextrusion Monofil GmbH. Available online: https:/www.perlon.com/wp-content/uploads/2019/05/ PER_PB_AntiStat_19_en_web.pdf (accessed on 12 May 2020).

10. Deng, H.; Lin, L.; Ji, M.; Zhang, S.; Yang, M.; Fu, Q. Progress on the morphological control of conductive network in conductive polymer composites and the use as electroactive multifunctional materials. Prog. Polym. Sci. 2014, 39, 627-655. [CrossRef]

11. Gulrez, S.K.; Mohsin, M.A.; Shaikh, H.; Anis, A.; Pulose, A.M.; Yadav, M.K.; Qua, E.H.P.; Al-Zahrani, S. A review on electrically conductive polypropylene and polyethylene. Polym. Compos. 2013, 35, 900-914. [CrossRef]

12. Kaur, G.; Adhikari, R.; Cass, P.; Bown, M.; Gunatillake, P. Electrically conductive polymers and composites for biomedical applications. RSC Adv. 2015, 5, 37553-37567. [CrossRef]

13. Gooneie, A.; Sapkota, J.; Shirole, A.; Holzer, C. Length controlled kinetics of self-assembly of bidisperse nanotubes/nanorods in polymers. Polymers 2017, 118, 236-248. [CrossRef]

14. Gooneie, A.; Hufenus, R. Hybrid Carbon Nanoparticles in Polymer Matrix for Efficient Connected Networks: Self-Assembly and Continuous Pathways. Macromolecules 2018, 51, 3547-3562. [CrossRef]

15. Sadeghi, S.; Arjmand, M.; Navas, I.O.; Yazdi, A.Z.; Sundararaj, U. Effect of Nanofiller Geometry on Network Formation in Polymeric Nanocomposites: Comparison of Rheological and Electrical Properties of Multiwalled Carbon Nanotube and Graphene Nanoribbon. Macromolecules 2017, 50, 3954-3967. [CrossRef]

16. Majidian, M.; Grimaldi, C.; Forró, L.; Magrez, A. Role of the particle size polydispersity in the electrical conductivity of carbon nanotube-epoxy composites. Sci. Rep. 2017, 7, 12553. [CrossRef] [PubMed]

17. Sapkota, J.; Gooneie, A.; Shirole, A.; Garcia, J.C.M. A refined model for the mechanical properties of polymer composites with nanorods having different length distributions. J. Appl. Polym. Sci. 2017, 134, 45279. [CrossRef]

18. Ma, P.-C.; Liu, M.-Y.; Zhang, H.; Wang, S.-Q.; Wang, R.; Wang, K.; Wong, Y.-K.; Tang, B.-Z.; Hong, S.H.; Paik, K.-W.; et al. Enhanced Electrical Conductivity of Nanocomposites Containing Hybrid Fillers of Carbon Nanotubes and Carbon Black. ACS Appl. Mater. Interfaces 2009, 1, 1090-1096. [CrossRef] [PubMed]

19. Gubbels, F.; Jerome, R.; Teyssié, P.; Vanlathem, E.; Deltour, R.; Calderone, A.; Parente, V.; Bredas, J.L. Selective Localization of Carbon Black in Immiscible Polymer Blends: A Useful Tool to Design Electrical Conductive Composites. Macromolecules 1994, 27, 1972-1974. [CrossRef] 
20. Sumita, M.; Sakata, K.; Hayakawa, Y.; Asai, S.; Miyasaka, K.; Tanemura, M. Double percolation effect on the electrical conductivity of conductive particles filled polymer blends. Colloid Polym. Sci. 1992, 270, 134-139. [CrossRef]

21. Katada, A.; Buys, Y.F.; Tominaga, Y.; Asai, S.; Sumita, M. Relationship between electrical resistivity and particle dispersion state for carbon black filled poly (ethylene-co-vinyl acetate)/poly (L-lactic acid) blend. Colloid Polym. Sci. 2005, 284, 134-141. [CrossRef]

22. Hufenus, R.; Reifler, F.A.; Maniura-Weber, K.; Spierings, A.; Zinn, M. Biodegradable Bicomponent Fibers from Renewable Sources: Melt-Spinning of Poly(lactic acid) and Poly[(3-hydroxybutyrate)-co-(3-hydroxyvalerate)]. Macromol. Mater. Eng. 2011, 297, 75-84. [CrossRef]

23. Rwei, S.-P.; Rwei, S.-P.; Cheng, K.-C. Dispersion of carbon black in a continuous phase: Electrical, rheological, and morphological studies. Colloid Polym. Sci. 2002, 280, 1110-1115. [CrossRef]

24. Ravindren, R.; Mondal, S.; Nath, K.; Das, N.C. Synergistic effect of double percolated co-supportive MWCNT-CB conductive network for high-performance EMI shielding application. Polym. Adv. Technol. 2019, 30, 1506-1517. [CrossRef]

25. Goldel, A.; Marmur, A.; Kasaliwal, G.R.; Pötschke, P.; Heinrich, G. Shape-Dependent Localization of Carbon Nanotubes and Carbon Black in an Immiscible Polymer Blend during Melt Mixing. Macromolecules 2011, 44, 6094-6102. [CrossRef]

26. Sumita, M.; Sakata, K.; Asai, S.; Miyasaka, K.; Nakagawa, H. Dispersion of fillers and the electrical conductivity of polymer blends filled with carbon black. Polym. Bull. 1991, 25, 265-271. [CrossRef]

27. Mamunya, Y.P. Morphology and percolation conductivity of polymer blends containing carbon black. J. Macromol. Sci. Part B 1999, 38, 615-622. [CrossRef]

28. Huang, J.-C. Carbon black filled conducting polymers and polymer blends. Adv. Polym. Technol. 2002, 21, 299-313. [CrossRef]

29. Baudouin, A.-C.; Devaux, J.; Bailly, C. Localization of carbon nanotubes at the interface in blends of polyamide and ethylene-acrylate copolymer. Polymer 2010, 51, 1341-1354. [CrossRef]

30. Cayla, A.; Campagne, C.; Rochery, M.; Devaux, É. Electrical, rheological properties and morphologies of biphasic blends filled with carbon nanotubes in one of the two phases. Synth. Met. 2011, 161, 1034-1042. [CrossRef]

31. Gooneie, A.; Nazockdast, H.; Shahsavan, F. Effect of selective localization of carbon nanotubes in PA6 dispersed phase of PP/PA6 blends on the morphology evolution with time, part 1: Droplet deformation under simple shear flows. Polym. Eng. Sci. 2015, 55, 1504-1519. [CrossRef]

32. Feng, J.; Chan, C. Carbon black-filled immiscible blends of poly(vinylidene fluoride) and high density polyethylene: Electrical properties and morphology. Polym. Eng. Sci. 1998, 38, 1649-1657. [CrossRef]

33. Zoldan, J.; Siegmann, A.; Narkis, M.; Alig, I. Dielectric Spectroscopy of Anisotropic Polypropylene/Nylon-66 Blends Containing Carbon Black. J. Macromol. Sci. Part B 2006, 45, 61-83. [CrossRef]

34. Tchoudakov, R.; Breuer, O.; Narkis, M.; Siegmann, A. Conductive polymer blends with low carbon black loading: Polypropylene/polyamide. Polym. Eng. Sci. 1996, 36, 1336-1346. [CrossRef]

35. Huang, J.-C.; Wu, C.-L.; Grossman, S.J. Carbon Black-Filled Conductive Polymers of Polypropylene, Ethylene Vinyl Acetate Copolymer, and Their Ternary Blends. J. Polym. Eng. 2000, 20. [CrossRef]

36. Tan, Y.; Song, Y.; Cao, Q.; Zheng, Q. Characterization of carbon black-filled immiscible polypropylene/polystyrene blends. Polym. Int. 2011, 60, 823-832. [CrossRef]

37. Yu, G.; Zhang, M.Q.; Zeng, H.M.; Hou, Y.H.; Zhang, H.B. Conductive polymer blends filled with carbon black: Positive temperature coefficient behavior. Polym. Eng. Sci. 1999, 39, 1678-1688. [CrossRef]

38. Pan, Y.; Liu, X.; Hao, X.; Starý, Z.; Schubert, D.W. Enhancing the electrical conductivity of carbon black-filled immiscible polymer blends by tuning the morphology. Eur. Polym. J. 2016, 78, 106-115. [CrossRef]

39. Xu, Z.; Zhao, C.; Gu, A.; Fang, Z.; Tong, L. Effect of morphology on the electric conductivity of binary polymer blends filled with carbon black. J. Appl. Polym. Sci. 2007, 106, 2008-2017. [CrossRef]

40. Chen, G.; Yang, B.; Guo, S. Nylon 6 induced morphological developments and electrical conductivity improvements of polypropylene/carbon black composites. J. Appl. Polym. Sci. 2009, 114, 1848-1855. [CrossRef]

41. Wu, G.; Li, B.; Jiang, J. Carbon black self-networking induced co-continuity of immiscible polymer blends. Polymer 2010, 51, 2077-2083. [CrossRef]

42. Bobeth, W. Textile Faserstoffe: Beschaffenheit und Eigenschaften; Springer: Berlin/Heidelberg, Germany, 1993. 
43. Loy, W. Chemiefasern für Technische Textilprodukte: Standardtypen; Deutscher Fachverlag: Modifikationen, Einsatzgebiete, 2008.

44. Moniruzzaman, M.; Winey, K.I. Polymer Nanocomposites Containing Carbon Nanotubes. Macromolecules 2006, 39, 5194-5205. [CrossRef]

45. Huang, Y.Y.S.; Ahir, S.V.; Terentjev, E.M. Dispersion rheology of carbon nanotubes in a polymer matrix. Phys. Rev. B 2006, 73, 125422. [CrossRef]

46. European Standard. Protective Clothing-Electrostatic Properties_Part 5: Material Performance and Design Requirements; DIN EN 1149-5; Beuth Verlag: Berlin, Germany, 2008.

47. European Standard. High-Visibility Warning Clothing for Professional Use-Test Methods and Requirements; DIN EN 471; Beuth Verlag: Berlin, Germany, 2006.

48. Underwriters Laboratories. Tests for Flammability of Plastic Materials for Parts in Devices and Appliances; UL94; Underwriters Laboratories: Northbrook, IL, USA, 1990.

(C) 2020 by the authors. Licensee MDPI, Basel, Switzerland. This article is an open access article distributed under the terms and conditions of the Creative Commons Attribution (CC BY) license (http://creativecommons.org/licenses/by/4.0/). 